\title{
A Theoretical and Experimental Analysis of Critical Buckling Force of Short and Long Cylindrical Shells with a Welded Seam Using Argon Method and their Comparison with a Seamless Cylindrical Shell
}

\author{
Ali GHORBANI ${ }^{1}$, Niloofar BAYAT ${ }^{2}$, Mohammad Mehdi NAJAFIZADEH $^{3}$ \\ ${ }^{1}$ Graduate Student, Mechanical Engineering, Azad University of Arak \\ ${ }^{2}$ Graduate Student, Mechanical Engineering, Azad University of Arak \\ ${ }^{3}$ Associate-professor, Mechanical Engineering, Azad University of Arak
}

\begin{abstract}
In this paper, seaming and seamless as well as short and long cylindrical shell buckling of aluminum 6063 which is under axial loading is taken into account. The used parts have equal mass and thickness and the seam is filled with argon method. An experimental test has been done bySANTAM-STM-250 device. Numerical analysis has been conducted by Abaqus Software, and precision of these models is measured by experimental results.
\end{abstract}

Keywords: buckling behavior, seamless cylindrical shells, seaming cylindrical shells, axial loading.

\section{Introduction}

Shells are one of the most abundant and diverse variety of construction forms that are found in the physical world around us. Shell structures are used widely in aerospace industry, marine structures, automobile manufacturing, large dams, shellceilings, piping lines, fluid transport structures, etc. Shells due to low weight, high strength and easy make are applied widely in industries. In terms of engineering, buckling is regarded as an introduction to deterioration of a shell form [1]. Ugural [2] predicted buckling load of cylindrical shells under uniform compressive load using the following formula:

$$
\sigma_{c r}=\frac{E}{\sqrt{3\left(1-v^{2}\right)}} \frac{t}{r}
$$

Where elasticity modulus ${ }^{v}$, Poisson's ratio, $t$ thickness and rare equal the radius. He used the above formula only for shells made of isotropic and elastic materials. In reference [3], the dynamic buckling of elastic cylindrical shells with variable thickness is examined in terms of a function of time. In reference [4], for the first buckling, cracked shells were proposed. The focus, in this reference, is on full circumferentially cracked cylindrical shells. The buckling load of these shells is almost half a crackless cylindrical shell. In reference [5], the concurrent effects of thickness variation along with the initial imperfection on heterogeneous composite shells under uniform axial compression is taken into account. In reference [6], the effects of

\footnotetext{
${ }^{1}$ Alighorbani994@gmail.com

2N.bayat7000@gmail.com

3M-najafizadeh@iau-arak.ac.ir
} 
thickness variation on the buckling load of the cylindrical shells under the effect of uniform axial compression are discussed. This thickness variation is created by corrosion or during making composite shells or rolled steel plates which are considered as an axial symmetrical form and small enough compared to the shell thickness. In reference [7], buckling analysis of short and long functionally graded cylindrical shells under thermal and mechanical loads are taken into consideration. Shell characteristics change very consistently from the inner surface to the outer one. Equilibrium and stability equations are concluded using the total potential energy equations, Euler equations and theoretical assumptions of first-order shear deformation. The critical temperature and compressive loads are calculated for both short andlong cylindrical shells. Comparison of equations shows geometry and loading type on the critical buckling loads of short and long functionally graded cylindrical shells of functional effects.In reference [8], thermal buckling issues in line with the cylindrical shells made of functional graded materials are analyzed. Based on the theory of Danelshell, equilibrium and stability equations of cylindrical shells subjected to thermal loading are presented. The material properties are assumed as a power function. The difference of buckling temperature is considered based on the effects of bulk ratio. In reference [9], the buckling behavior of the functionally graded cylindrical shells under axial compression with geometric imperfections is analyzed by the theory of Danelshell and nonlinear straindis placement nonlinear relations for large deformation. The critical buckling load for incomplete functionally graded cylindrical shells is obtained using Galerkin method. The numerical results indicate the diverse effects of imperfection, simple type, power law, and temperature as well as dimensional parameters on the buckling.

In reference [10], free vibration and stability of functionally graded cylindrical shells are presented in accordance with high-order two dimensional deformation theory that by using a power series expansion method of shell displacement components, a bunch of governing fundamental equations are resulted from Hamilton law. A bunch of approximate theories to solve problems with special values of FG cylindrical shells can be used with a simple support. Critical buckling stresses of FG cylindrical shells with a simple support which is exposed to an axial stress are also obtained, and a relationship between buckling stress and natural frequency is presented. Normal transverse shear stresses are calculated by integration of threedimensional equations of motion in line with thickness in order to satisfy the boundary conditions of stress at the external and internal level. The high-order two dimensional deformation theory has an advantage to analyze vibration issues and buckling of FG cylindrical shells.

In reference [11], mechanical buckling of the functionally graded cylindrical shells is analyzed on elastic foundation. In this study, the mechanical buckling of functionally graded cylindrical shells in an elastic environment and exposed to combined axial loads and a radial pressure is described. Theoretical formula based on the high-order two dimensional deformation theory is presented considering the transverse shear strain. In reference [12], nonlinear elastic buckling and pre-buckling of axially compressed functionally graded cylindrical shells are put into account. Based on Great Leap Theory of Danel hypotheses, in this paper, nonlinear buckling and pre-buckling analyses are presented using Ritz method and nonlinear shift-strain relations on large deformation. The material properties will change 
gently in line with thickness according to power law distribution of volumetric fraction of constructive materials.

In reference [13], thermal elastic buckling of a thin cylindrical shell is analyzed based on improved stability equations. In this paper, Euler equations are used for functional energy and general thermo-elastic nonlinear equations of shell theory is compared with Danel equations.

In reference [14], thick hollow two-dimensional functionally graded cylindrical dynamic analysis with limited length was conducted. The axial symmetrical conditions are assumed for two-dimensional functionally graded cylinders. Finite element method with characteristics of graded materials is used for modeling of structures in each element; Newmark direct integration method is executed for solving time-dependent equations, and the time history of displacements, stresses and the phenomenon of two-dimensional wave are considered for different values of volume ratio powers.

With precision and search in conducted research, no laboratory and theoretical research has been carried out on seaming and seamless cylindrical shells yet, and in this study, two types of seaming and seamless cylindrical shell of aluminum 6063 have been taken into account.

\section{GEOMETRY OF SAMPLES:}

In this paper, shells with two seaming and seamless cylindrical differences with the same thickness $1.2 \mathrm{~mm}$, length $330 \mathrm{~mm}$, external diameter equal to $76.2 \mathrm{~mm}$ and inner diameter equal to $73.8 \mathrm{~mm}$ have been considered where $\mathrm{D}$ is as large diameter, $\mathrm{d}$ as small diameter, $\mathrm{h}$ as height and $t$ as medium thickness. The studied samples are made of aluminum 6063. Elastic modulus is assumed as 70Gpa, yield stress as $48 \mathrm{mpa}$ and Poisson's ratio as 0.33 .

\section{BONDARY CONDITIONS:}

To apply the load, the samples are placed by a rigid plate or rigid column separately under an axial force. Also, all freedom degrees of the bottom plate are fixed, and the top plate or column is free in movement in the axial direction. Moreover, for a numerical analysis of cylindrical shells by Abaqus software, S4R element which is a rectangle or four-hop linear element is used.

\section{RESULTS AND DISCUSSION:}

To compare the theoretical values of seaming and seamless cylinders, the Abaqus software is used. Given that a theoretical formula is not presented for the seaming cylinders, therefore, the Abaqus software is considered as an appropriate method for comparing experimental results. A theoretical analysis for shells predicts the buckling load more than the experimental value. Nevertheless, for all the theoretical samples in software, first a linear analysis is conducted to obtain modes having special and more appropriate values; otherwise, the software selects a buckling mode optionally that usually leads to unrealistic results. For the buckling analysis, Abaqus/Standard is applied. The main purpose of this paper is to study the buckling load of seaming as well as seamless cylindrical pipes and to compare them with one another so that geometry of parts is the same in terms of length, diameter and thickness. The pipes are made of aluminum 6063, and testing of parts is done by SANTAM-STM-250 device (Figure 1) 

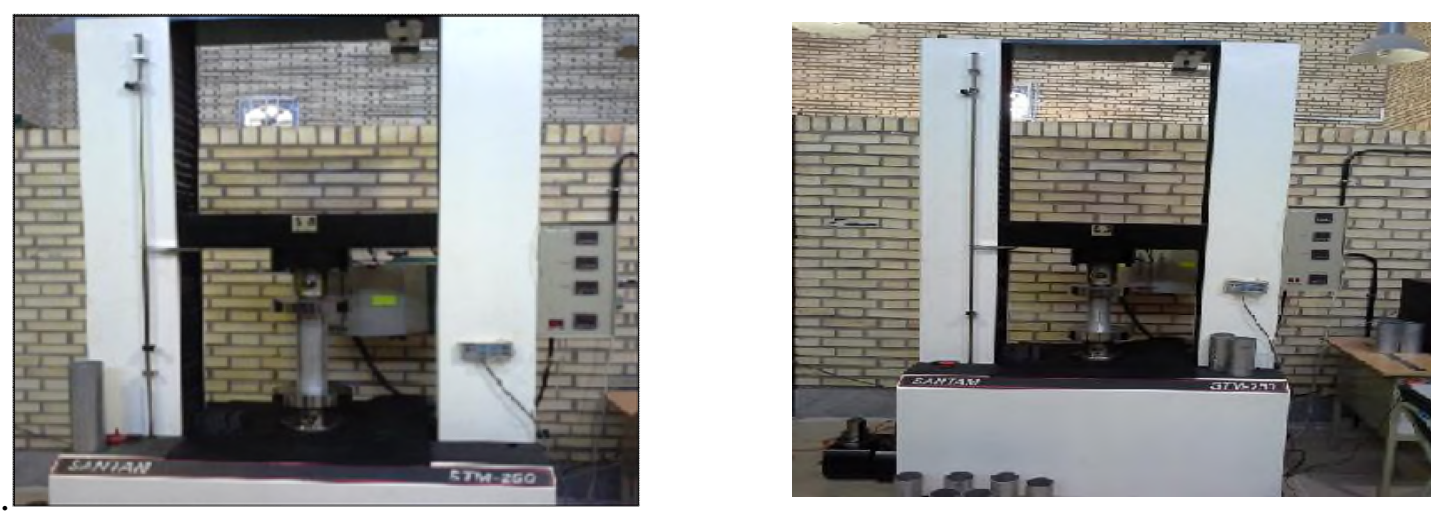

Fig. 1\& 2: Short and long cylindrically buckling shells using a pressing device

The samples are tested experimentally so that all cylinders are placed between two jaws of the device; the force is entered into them to some extent that displacement occurs in the upper jaw, and it is moved to the bottom side; then, the load value from the device is considered at the time of displacement and is used for analysis of the results. Two models of seaming and seamless cylinders are put into consideration of the studied displacement. The results of buckling load value for the seamless cylinder is less than the seaming one indicating that in structures that need to bear greater axial buckling load, the use of seaming cylinders is appropriate. Considering the seaming experimental diagram, it can be observed that the axial load value of the seaming cylindrical buckling is far more than that of the seamless cylindrical buckling.

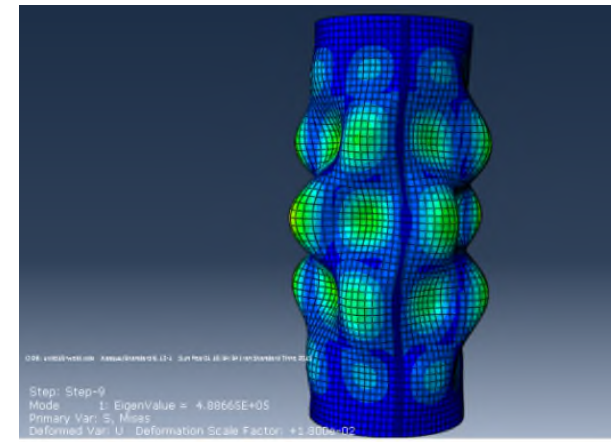

Fig. 3: Short seaming cylindrical buckling

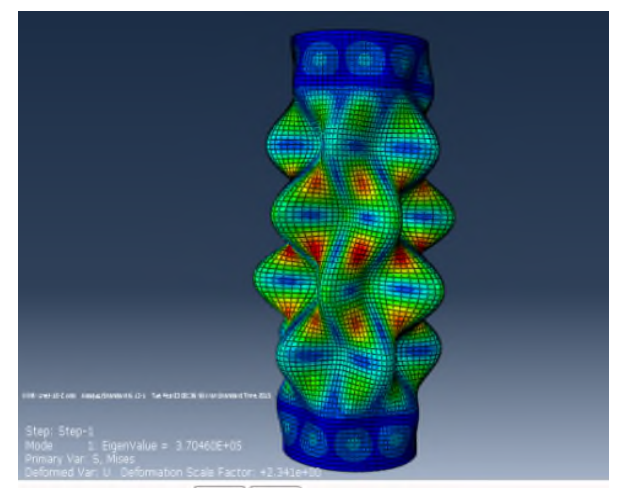

Fig. 5: Short seamless cylindrical buckling

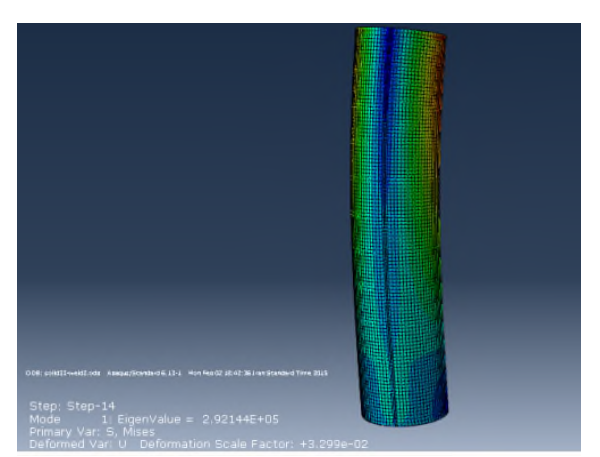

Fig. 4: Long seaming cylindrical buckling

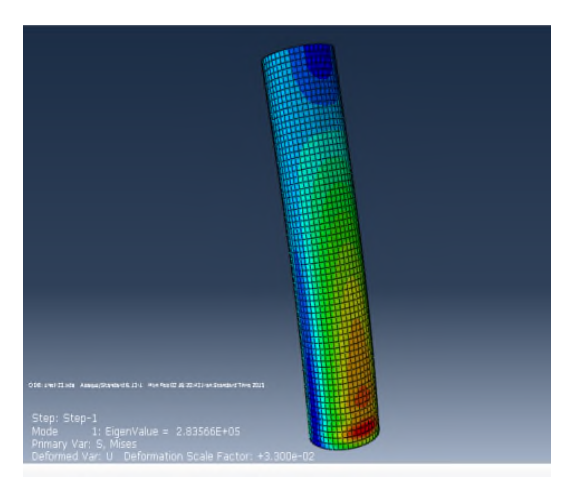

Fig.6: Long seamless cylindrical buckling 


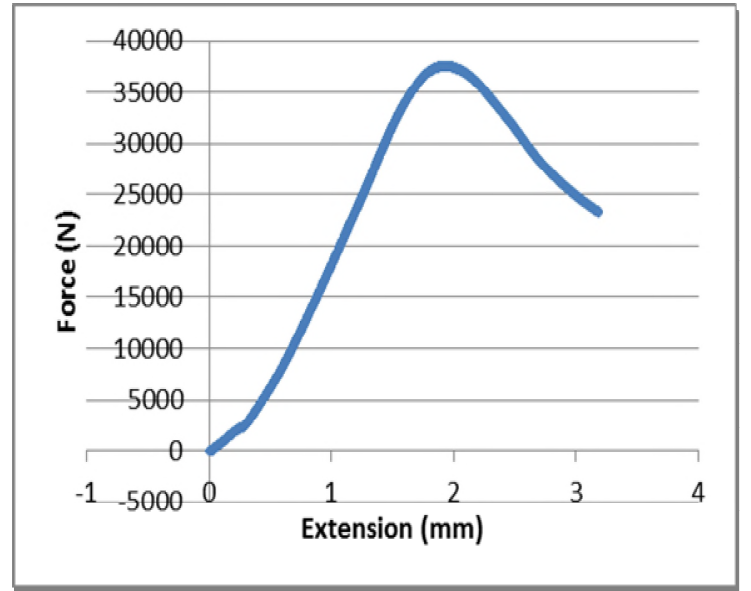

Fig. 7: Theoretical diagram of a short seaming cylindrical shell

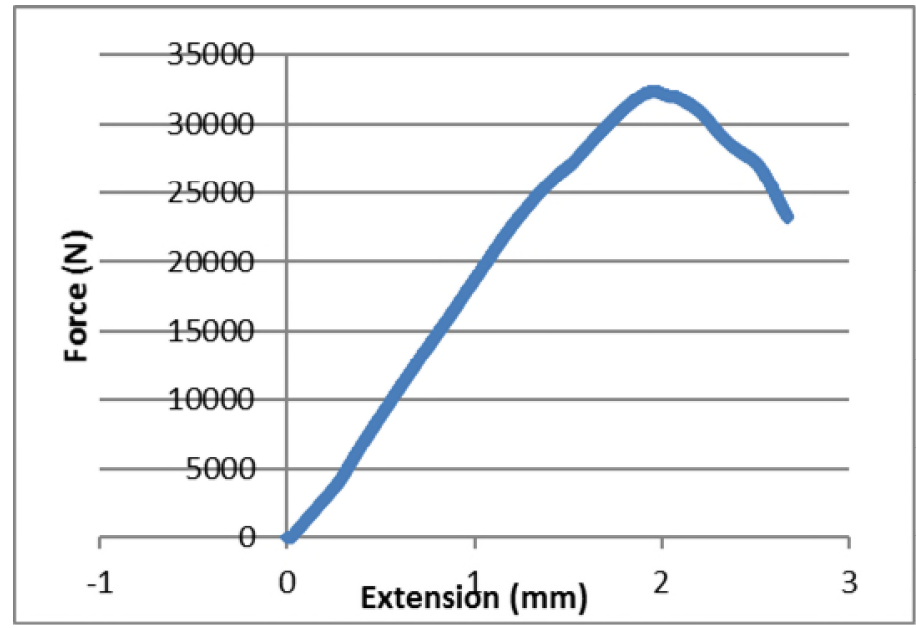

Fig. 8: Theoretical diagram of a long seaming cylindrical shell

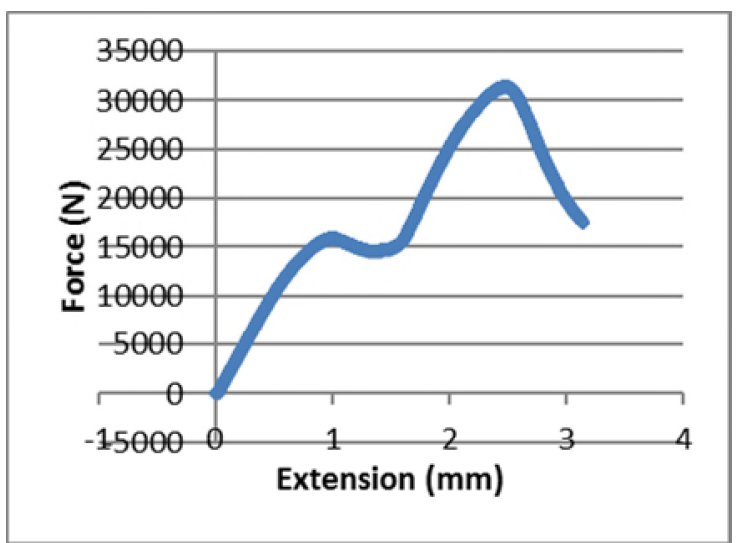

Fig.9: Theoretical diagram of a short seamless cylindrical shell 


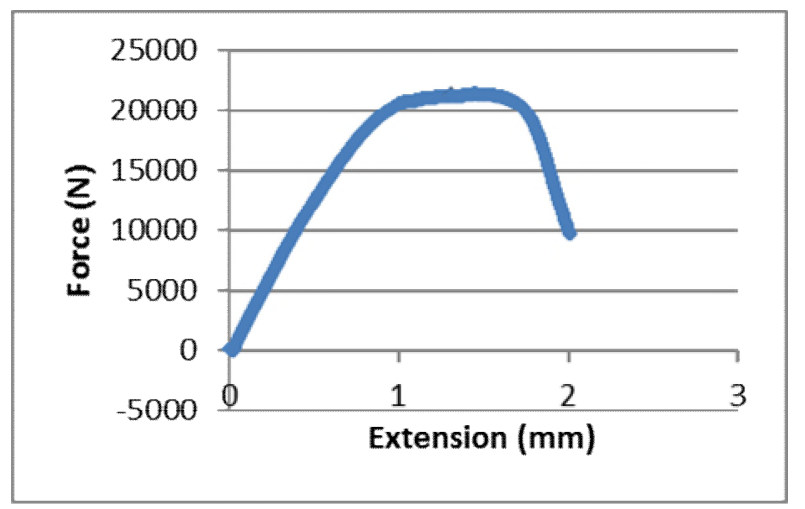

Fig.10: Theoretical diagram of a long seamless cylindrical shell

\begin{tabular}{|c|c|c|c|c|c|c|c|c|c|}
\hline \multicolumn{10}{|c|}{ 6063aluminumpipewith a length of $180 \mathrm{~mm}$} \\
\hline $\begin{array}{l}\text { Type of } \\
\text { Pipe }\end{array}$ & $\begin{array}{c}\text { Theoretical } \\
\text { Force }\end{array}$ & $\begin{array}{c}\text { Shell } \\
\text { Abaqus } \\
\text { Force }\end{array}$ & $\begin{array}{c}\text { Solid } \\
\text { Abaqus } \\
\text { Force }\end{array}$ & $\begin{array}{c}\text { Experimental } \\
\text { Force }\end{array}$ & $\begin{array}{c}\text { Experimental } \\
\text { and } \\
\text { Theoretical } \\
\text { Error } \\
\text { Percentage }\end{array}$ & $\begin{array}{c}\text { Shell Abaqus } \\
\text { Experimental } \\
\text { Error } \\
\text { Percentage }\end{array}$ & $\begin{array}{c}\text { Shell } \\
\text { Abaqus } \\
\text { Theoretical } \\
\text { Error } \\
\text { Percentage }\end{array}$ & $\begin{array}{c}\text { Solid Abaqus } \\
\text { Experimental } \\
\text { Error } \\
\text { Percentage }\end{array}$ & $\begin{array}{c}\text { Solid } \\
\text { Abaqus } \\
\text { Theoretical } \\
\text { Error } \\
\text { Percentage }\end{array}$ \\
\hline Seaming & $3 / 778 \times 10^{5}$ & $3 / 70460 \times 10^{5}$ & $4 / 22140 \times 10^{5}$ & $3 / 13430 \times 10^{5}$ & $20 / 51$ & $15 / 38$ & $1 / 98$ & $25 / 75$ & $10 / 5$ \\
\hline Seamless & - & - & $4 / 88665 \times 10^{5}$ & $3 / 75723 \times 10^{5}$ & - & - & - & $23 / 1$ & - \\
\hline
\end{tabular}

Table 1: Comparison of experimental and theoretical results for short cylinders (software analysis)

\begin{tabular}{|c|c|c|c|c|c|c|c|c|c|}
\hline \multicolumn{10}{|c|}{ 6063aluminumpipewith a length of $330 \mathrm{~mm}$} \\
\hline $\begin{array}{l}\text { Type of } \\
\text { Pipe }\end{array}$ & $\begin{array}{c}\text { Theoretical } \\
\text { Force }\end{array}$ & $\begin{array}{c}\text { Shell Abaqus } \\
\text { Force }\end{array}$ & $\begin{array}{l}\text { Solid } \\
\text { Abaqus } \\
\text { Force }\end{array}$ & $\begin{array}{l}\text { Experimental } \\
\text { Force }\end{array}$ & $\begin{array}{l}\text { Experimental } \\
\text { and } \\
\text { Theoretical } \\
\text { Error } \\
\text { Percentage }\end{array}$ & $\begin{array}{c}\text { Shell Abaqus } \\
\text { Experimental } \\
\text { Error } \\
\text { Percentage }\end{array}$ & $\begin{array}{l}\text { Shell Abaqus } \\
\text { Theoretical } \\
\text { Error } \\
\text { Percentage }\end{array}$ & $\begin{array}{c}\text { Solid Abaqus } \\
\text { Experimental } \\
\text { Error } \\
\text { Percentage }\end{array}$ & $\begin{array}{c}\text { Solid } \\
\text { Abaqus } \\
\text { Theoretical } \\
\text { Error } \\
\text { Percentage }\end{array}$ \\
\hline Seaming & $3 / 778 \times 10^{5}$ & $2 / 83566 \times 10^{5}$ & $\underset{5}{2 / 98826 \times 10}$ & $2 / 14226 \times 10^{5}$ & $43 / 29$ & $24 / 43$ & 25 & $28 / 31$ & 21 \\
\hline
\end{tabular}

Table 2: Comparison of experimental and theoretical results for long cylinders (software analysis)

The maximum difference in buckling analysis with Abaqus software is almost 10 times higher than the experimental results that will be examined for axially compressed cylindrical shells with Batdorft parameter. With comparisons made; considering the logarithmic graph Figure (6), and comparison of Ka theoretical and experimental coefficients, it can be specified clearly that the experimental results are far less than the results of the theoretical ones. Generally, from the difference factors between numerical and experimental results, we can refer to the existence of imperfections and defects in a material, error in machining, turning on a piece, etc. 


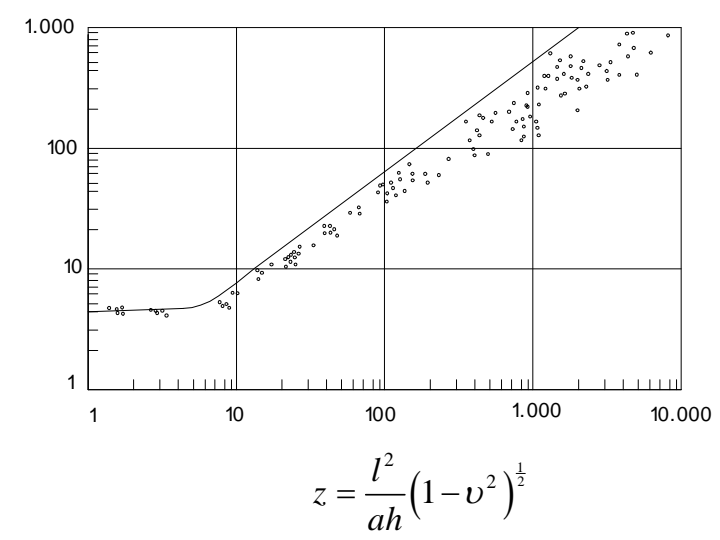

Fig. 11: Comparison of theoretical and experimental values for compressed cylinders

\section{CONCLUSION:}

The extent of the critical buckling load for cylindrical collapse means the area where a cylinder can be entered into a plastic environment for two types of seaming as well as seamless cylindrical shells that were taken into account in this project. Often, theoretical analyses present the extent of an appropriate critical buckling load for thin cylindrical shells that these analyses are dependent on the cylindrical geometry, including length, thickness, material and the operation done on pipes like welding. The value of buckling load obtained from software analysis when the object is considered as a form of shell is less than the theoretical value and also when the object is drawn as a form of solid in software. Given that the amount of experimental buckling load is less than software analysis, so an experimental sample shall surely be used in doing projects. As it was mentioned, the extent of the critical buckling load is dependent on the geometric shape that considering geometric deformation of the cylinder and its turning into a cylinder with an Argon welded seam, the amount of the obtained buckling load from the software and experimental analysis is more than that of a seamless cylindrical pipe; therefore, to perform projects that their resistance to buckling is sensitive, be sure to make use of seaming pipes.

\section{REFRENCES:}

[1] Farshad, M., Theoretical Principles of Shell Construction, University of Shiraz, 1987.

[2] Ugural, A.C., Stresses in Plates and Shells, New York, (1981) McGraw-Hill

[3] Aksogan, O., Sofiyev A. H., Dynamic Buckling of a Cylindrical Shell with Variable Techniques subject to a Time-Dependent External Pressure Varying as a Power Function of Time, Journal of Sound and Vibration, (2002) 254 (4): 693-702.

[4] Naschie, M.S., Branching Solution for Local Buckling of a Circumferentially Cracked Cylindrical Shell, International Journal Mechanics Science, (1974) 16:689-97. 
[5] Yi-W.Li, I.Elishakoff, J.H.Stames,D.Bushnell,Effect of the Thickness Variation and Initial Imperfection on Buckling of Composite Cylindrical Shell: Asymptotic Analysis and Numerical Results by Bosor 4 and Panda 2, Journal of Solid Structures, (1997) 34(28):37553767.

[6] W.T.Koiter, I.Elishakov, Y.W.LeeandJ.R.Straness, Buckling of Axially Compressed Cylindrical Shell of Variation Thickness, International Journal of Solid Structures, (1994) 31(30):797-805.

[7] O.Miraliyari, M.M.Najafizadeh, A.R.Rahmani, and A.MomeniHezaveh., Thermal and Mechanical Buckling of Short and Long Functionally Graded Cylindrical Shells Using First Order Shear Deformation Theory, |World Academy of Science Engineering and Technology, (2011) 74.

[8] LanheWu,Zhiqing Jiang, Jun Liu.Thermoelastic Stability of Functionally Graded Cylindrical Shells, Composite Structures, (2005) 70:60-68.

[9] HuaiweiHuang,QiangHan.Buckling of Imperfect Functionally Graded Cylindrical Shells under Axial Compression, European Journal of Mechanics A/Solids, (2008) 27: 1026-1036.

[10] Hiroyuki Mitsunaga. Free Vibration and Stability of Functionally Graded Circular Cylindrical Shells according to a2D Higher-Order Deformation Theory, Composite Structures, (2009) 88:519-531.

[11] E.Bagherizadeh, Y.Kiani,M.R.Eslami.Mechanical Buckling of Functionally Graded Material Cylindrical Shells Surrounded by Pasternak Elastic Foundation, Composite Structures,(2011).

[12] Huaiwei Huang, QiangHan.Nonlinear Elastic Buckling and Postbuckling of Axially Compressed Functionally Graded Cylindrical Shells, International Journal of Mechanical Sciences, (2009) 51:500-507.

[13] M.R.Eslami, A.R.Ziaii, and A.Ghorbanpour. Thermoelastic Buckling Of Thin Cylindrical Shells Based on Improved Stability Equations, Journal of Thermal Stresses, (1996)19:299-3154.

[14] Hui-Shenshen,Chen-Li Zhang. Thermal Buckling.Thermal Buckling and Postbuckling Behavior Functionally Graded Carbon Nanotube-Reinforced Composite Plates Material and Design, (2010) 313:403-3411. 